\title{
Does the effectiveness of forest protected areas differ conditionally on their type of governance?
}

\author{
Biljana Macura ${ }^{1,2^{*}}$, Laura Secco ${ }^{1}$ and Andrew S Pullin ${ }^{2}$
}

\begin{abstract}
Background: In context of protected areas (PAs), governance can be defined as a set of processes, procedures, resources, institutions and actors that determine how decisions are made and implemented. Current governance modes of forest PAs are multilevel and complex, with a variety of actors, different levels of power sharing, various formal and informal rules and vested interests. However, there is no systematic information on how different local governance modes and day-to-day decision-making processes within forest PAs may cause a change in PA effectiveness in terms of producing desired conservation outcomes. In this review we aim to assess relative effectiveness of forest PAs worldwide with respect to different governance modes and linking them to the multiple outcomes in order to discern the effective governance strategies for biodiversity and forest conservation. We will evaluate effectiveness of forest protected areas by multiple outcome measures: 1) attitudes of local stakeholders towards forest protected area governance, 2) conservation-related behaviour of local stakeholders, 3) ecological parameters such as forest cover, biodiversity level, density, overall forest condition and/or health as well as 4) existence of local spillover effects defined as social, institutional and ecological effects in surrounding social-ecological systems.

Methods: To gather empirical evidence on the effectiveness and outcomes of different governance arrangements of forest protected areas, we will search electronic databases, organizational websites, use web search engines and perform a bibliographic search. Articles will be filtered by title, abstract and full text. To facilitate understanding of predictors and conditions for effective PAs, both qualitative and quantitative data from the relevant studies will be extracted and integrated. Multivariate statistical analyses will be performed to give insights into association between different governance modes, their characteristics and PA effectiveness. Finally, the review will report on data gaps and potential for future empirical research.
\end{abstract}

Keywords: Evidence synthesis, Systematic review, Biodiversity conservation, Assessment, Evaluation, Conservation success, Participation, Ecological outcomes

\section{Background}

Forests contain roughly $90 \%$ of terrestrial biodiversity and they provide a wide variety of ecosystem services, contributing to the livelihoods of more than 1 billion people [1]. Yet, forest degradation and deforestation are advancing at alarming rate, especially in the tropics [2] and are putting at risk a high diversity of species and habitats sustained by forest ecosystems [3].

\footnotetext{
* Correspondence: biljana.macura@studenti.unipd.it

'Department of Land, Environment, Agriculture and Forestry (TESAF), University of Padua, Viale dell'Università 16, 35020, Agripolis, Legnaro (PD), Italy

${ }^{2}$ Centre for Evidence-Based Conservation, School of Environment, Natural Resources and Geography, Bangor University, Gwynedd, LL57 2UW, UK
}

Establishment of in situ conservation strategies, such as protected areas (PAs), has been the major response to a global demand for conservation of biodiversity and ecosystem services [4] and more specifically, to the reduction of tropical deforestation [5]. Accordingly, there has been a year-on-year increase in the number of PAs and they are today covering more than $12 \%$ of the total world's land surface [6] and $13.5 \%$ of the world's forests [3].

Nevertheless, the effectiveness of biodiversity and forest conservation measures ${ }^{a}$ is under question as the rate of biodiversity loss is not decelerating [7]. There is evidence that PAs are decreasing the deforestation rate $[5,8]$, estimated through measures of land clearing prevention [9] and decreasing the incidence of forest fires

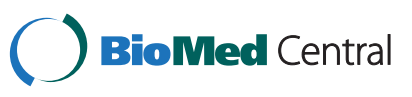


[10]. However, some authors argue that many of the claimed positive conservation effects might be a function of a PA location i.e. low accessibility of protected land, but not the effect of actual protection measures [5,11]. Additionally, increasing deforestation and pressures on the resources in social-ecological systems that surround PAs, might diminish conservation efforts inside PAs, through effects of ecological isolation and landscape fragmentation $[8,12]$.

However, there is no systematic information on how different local governance modes and day-to-day decision-making processes within forest PAs may cause a change in PA effectiveness in terms of producing desired conservation outcomes. In context of PAs, governance can be defined as "a set of processes, procedures, resources, institutions and actors that determine how decisions are made and implemented" ([13]:105). It is about power, relationships, accountability and responsibility exercised by organisations and actors [14,15]. Conservation governance arrangements are becoming multilevel and complex [16]. Governments are not the only source of environmental decision-making authority and there is a shift from administrative to collaborative state [17]. Power to make and enforce decisions is distributed among diverse social actors [18], including indigenous, mobile and local communities, local governments, NGOs and the private sector [19]. The change of the scale of governance has been occurring (mostly in the developing countries), and the authority and responsibility to make and enforce decisions are shifted from nation-state to lower-level authorities (decentralization) or to institutions outside the state (devolution) [20,21].

Following the main trends in conservation governance and based on the power distribution and scale of decisionmaking, type of different actors involved and level and nature of their collaboration, four broad modes of PAs governance can be identified [15,19]: 1) governance by government, 2) shared governance or co-management, 3) private governance and 4) governance by communities and indigenous people. These governance modes are briefly described in the following paragraphs as each of them may deliver different social and ecological outcomes.

1) Government PAs are governed by the centralised governmental agency (ministry or park agency reporting directly to the government) that enforces decisions, has authority, responsibility and accountability for managing PAs [15]. Government agencies are often considered as legitimate actors that can deliver public benefits and are accountable directly to the public [22]. Nevertheless, some authors argue that this 'old' [23] hierarchical type of governance is not able to handle size and complexity of PAs [19]. Moreover, state PAs with top-down and exclusionary conservation approach, frequently present in developing world, are being increasingly reported to produce unequal distribution of rights, power and benefits and create social conflicts [24].

2) Co-managed or multi-stakeholder PAs are governance modes where a governmental agency and other stakeholders, such as local/mobile/indigenous communities that depend on the area culturally or for their livelihoods, or user associations, private entrepreneurs and landowners share power and responsibility, make and enforce decisions. Formal decision-making authority might be vested in one agency (often governmental body), but that agency is required by law to collaborate with other stakeholders [25]. This collaborative partnership may be materialised through many forms: from consultation to decision-making carried out by consensus 15]. Co-management is frequently labeled as managing relationships, not resources [26,27]. However, it is argued that the partnerships in co-management arrangements can be problematic as nature of power sharing makes less powerful partners, such as indigenous people, disadvantaged [28].

3) Private PAs where private landowners, individuals, NGOs and other not-for profit and for-profit organisations make and enforce decisions, have control and/or ownership over resources. PAs can be governed by private and non-governmental actors, that might be perceived more efficient than bureaucratic structure of governmental agencies, also providing technical and financial support, bringing new ideas and capacity building [22]. However, the legitimacy and accountability of private parties is always limited and questionable, especially due to the vested interests of funding agencies and reluctance of governments to give authority or legal recognition to private parties [22,25]. Moreover, since designation of a private PA is a voluntary act, providing long-term security for conservation may pose a challenge [25].

4) Community conserved areas ${ }^{\mathrm{b}}$ are governed and voluntarily conserved by indigenous groups, local and mobile communities through customary laws. Authority and responsibility is vested within communities through a variety of ethnic governance or locally arranged rules and organisation that can be very complex, with diverse management and ownership rights. Community conserved areas depend on the government recognition and respect of community/indigenous rights over the territory [15]. However, community based conservation are criticised to be vulnerable to external drivers and not being able to deal with larger scale biodiversity processes (e.g. management of migratory species) [29].

Fifth, hybrid governance type may be added to this classification as in the reality borders between governance modes are blurred [30] and this is especially because of complex land and resource ownership rights, diversity in management authority and funding sources [31]. 
Nevertheless, the importance of the local political processes within PAs is frequently ignored in the conservation effectiveness literature. Therefore, to improve PAs governance and their conservation outcomes, there is need for more clear information on how differences in local governance modes and decision-making processes may cause variability in the outcomes and thus, in the effectiveness of forest PAs.

Four previous Systematic Reviews have addressed the various aspects of community-based conservation, synthesising and assessing primary literature on: 1) development as a conservation tool [32]; 2) the effect of local cultural context [33] and 3) broader social - political context on community based management [34], and 4) community forest management as a mechanism for supplying global environmental benefits and improving local welfare [35]. There are two more Systematic Reviews that have a wider conservation focus on terrestrial PAs and their 1) effectiveness in maintaining biodiversity and reducing habitat loss [36] and 2) securing human-well being (in preparation) [37]. This Systematic review is complementary to previous ones, looking from the governance perspective on effectiveness of forest protected areas worldwide; and determining the links between governance processes and multiple conservation outcomes.

Due to high complexity and variety of conservation practices, we will focus our analysis on conservation of forest resources only and on governance of forest PAs. To be defined as a PA, conservation governance arrangements have to: 1) have geographical limits or boundaries; 2) predominantly aim to achieve conservation benefits, but not excluding other related benefits (e.g. social benefits); 3) be designated and managed by legal gazetted means or by non-gazetted, but officially recognized NGO policies or customary laws; 4) have a body of governing rules; and 5) have a clearly identified organization or individual with a governance authority $[25,38]$. We define forest PAs as "a subset of all protected areas that includes a substantial amount of forest as defined for the purposes of Forest Protected Areas. This may be the whole or a part of a protected area" ([39]:19). This IUCN's definition excludes commercial plantations and forest managed for industrial purposes within the less strictly protected categories [39].

\section{Objectives of the review}

We aim to assess relative effectiveness of different governance regimes within forest PAs by contrasting different governance characteristics and processes on the basis of multiple measures of success ${ }^{c}$.

There are recently quite a few studies that have estimated effectiveness of PAs (e.g. [40-42]), but they have focused solely on the tropics and only few of them assessed
PAs effectiveness integrating multiple performance measures [43-45]. Apart from biodiversity conservation, PAs have various multifaceted and context-dependent objectives [43], in both, ecological and the social-economic domain. Examining PAs effectiveness in terms of biodiversity conservation only, might lead to restricted conclusions as it disregards local conflicts and resistance expressed through negative attitudes towards conservation policies and practices and anti-conservation behaviour of local stakeholders; it does not take into account institutional, economical or political changes in surrounding socialecological systems influenced by PAs (e.g. employment opportunities or migration level) and it may reinforce a fortress conservation mentality [43-50].

In this review, we look at the following outcome measures:

A) Outcome measures within forest PA boundaries:

1) Attitudinal success measured through (difference/ change in) attitudes of local stakeholders ${ }^{\mathrm{d}}$ towards focal PA, authority and/or management practices

2) Behavioural success measured through (difference/change in) level of conservationoriented behaviour necessary to decrease the threats to natural resources (e.g. decrease in level of illegal activities, poaching, etc.)

3) Ecological success measured through (difference/ change in) deforestation rate, biodiversity level, maintenance of forest cover and forest density, condition, health.

B) Outcome measures outside of forest PAs boundaries:

4) Spillover effects in surrounding social-ecological systems i.e. social, institutional and ecological changes on the local level including [5]: displacement of deforestation and agricultural pressures, preventive clearing at the nearby private land to prevent protective regulation, establishment of private reserves, better law enforcement at the neighbouring land, reforestation initiatives, new employment opportunities and similar. The spillover effects will be included into analysis only if there are reported baseline data against which these effects might be defined and measured [51]. Because of practical reasons, these changes will be recorded only at the local level that might be at a lowest administrative unit where a PA is located (e.g. municipality).

This review aims at answering following primary question:

Does the effectiveness of forest protected areas differ conditionally on their type of governance?

Elements of the primary question are shown in the Table 1. 
Table 1 Elements of the systematic review question

\begin{tabular}{|c|c|c|c|c|}
\hline Setting & Perspective & Interest, phenomena of & Comparison & Evaluation \\
\hline \multirow{6}{*}{$\begin{array}{l}\text { Forest protected } \\
\text { areas }\end{array}$} & 1. Local Community & 1. Governmental PAs & \multirow{6}{*}{$\begin{array}{l}\text { 1. With different } \\
\text { governance regimes }\end{array}$} & \multirow{2}{*}{$\begin{array}{l}\text { 1) Attitudinal success measured through } \\
\text { (difference/change in) attitudes of local stakeholders } \\
\text { towards focal PA, authority and/or management } \\
\text { practices }\end{array}$} \\
\hline & $\begin{array}{l}\text { 2. PA Authority/ } \\
\text { Management staff }\end{array}$ & 2. Co-managed PAs & & \\
\hline & & 3. Private PAs & & \multirow{2}{*}{$\begin{array}{l}\text { 2) Behavioural success measured through } \\
\text { (difference/change in) level of conservation-orientec } \\
\text { behaviour necessary to decrease the threats to } \\
\text { natural resources }\end{array}$} \\
\hline & & $\begin{array}{l}\text { 4. Community } \\
\text { conserved areas }\end{array}$ & & \\
\hline & & 5. Hybrid forms & & $\begin{array}{l}\text { 3) Ecological success measured through } \\
\text { (difference/change in) deforestation rate, } \\
\text { biodiversity level, maintenance of forest cover and } \\
\text { forest density, condition, health, etc }\end{array}$ \\
\hline & & & & $\begin{array}{l}\text { 4) Spillover effects: social, institutional and ecological } \\
\text { changes in surrounding social-ecological systems }\end{array}$ \\
\hline
\end{tabular}

Secondary question is:

Which characteristics of decision-making process influence the outcomes of forest protected areas?

Based on the aforementioned trends in PA governance, we selected following analytical variables that might describe governance processes:

1) Scale of decision-making:

1.1) Level of decentralization i.e. level of implementation of "subsidiarity" principle (central decision-making, decentralization or devolution);

2) Individual versus multi-actor decision-making:

2.1) Diversification of stakeholders' categories (one versus multi-actor);

2.2) Nature of stakeholders' participation (pro-active, consultancy, passive, none);

3) Collaboration among stakeholders in decision-making: 3.1) Nature of collaboration (formal, informal, none);

3.2) Level of collaboration (horizontal/internal, vertical/external, multilevel);

We assume that governance processes i.e. how decisions are made and implemented, influence level of conservation effectiveness, its ecological and social outcomes. Using theory of change approach, we hypothesise that: (H1) making decisions at lowest level possible, (H2) collective or multiactor decision making, (H3) high level of proactive participation in day-to-day decision-making and (H4) multilevel collaboration among stakeholders can lead to more positive attitudinal, behavioural and ecological success of PAs and decrease negative spillover effects around them.

\section{Methods}

\section{Search strategy}

We will search for all available evidence relevant to the questions, whether published or unpublished, including both peer reviewed papers and relevant grey literature.

\section{Publication databases}

The general search will be conducted using the following online databases:

ISI Web of knowledge
Scopus
PubMed
Agricola
International Development Research Center (IDRC)
digital library
Scienceindex
Public library of science
Directory of Open Access Journals
COPAC
Social Sciences research network
Index to Theses Online
CAB Abstracts

\section{Web search engines}

Due to repeatability, the web search will be mainly used for reference cross-checks. Following web search engines will be used:

1) www.scholar.google.com

2) http://scientific.thomsonwebplus.com/

3) www.scirus.com (web sources only)

Only the first 50 hits of each search will be screened.

\section{Organisational website search}

Specific searches will be conducted using the following websites of organisations specialised in the field of (forest) PA management and governance. Where possible, only publication sections of the websites will be used for search. List of websites was compiled from previous Systematic Reviews on effectiveness of PAs and community-based conservation [32-37] and completed by including websites of 
organisations well-known in the field of natural resource governance, forestry and PAs.

http://www.agter.org//

http://www.capri.cgiar.org/

http://www.catie.ac.cr/Magazin_ENG.asp?

CodIdioma $=$ ENG

http://www.cbnrm.net/

http://www.cgiar.org/

http://www.cifor.org/

http://www.cof.orst.edu/org/istf/ftpp.htm

http://www.communityforestryinternational.org/

http://www.conservation.org

http://www.cooperationcommons.com/

http://www.culturalsurvival.org/

http://cfs.nrcan.gc.ca/publications

http://community.eldis.org/

http://www.conservationgateway.org/Pages/Advanced-

Search.aspx $/$

http://seslibrary.asu.edu/seslibrary/search

https://dec.usaid.gov/dec/home/Default.aspx\#

https://www.gov.uk/government/organisations/

department-for-international-development

http://www.eci.ox.ac.uk/publications/index.php

http://www.eldis.org/

http://www.etfrn.org

http://www.fao.org/documents/en/search/init/,

http://www4.fao.org/faobib/

http://www.firstpeoples.org/

http://www.forest-trends.org/publications.php

http://forests.org/

http://www.ifad.org/

http://www.iied.org

http://iog.ca/

http://www.indiana.edu/ workshop/publications/

index.php

http://www.iucn.org/knowledge/publications_doc/

http://www.iufro.org/publications/

http://www.lib.umn.edu/cgi-bin/forestry/index.cgi

http://www.nzdl.org/fast-cgi-bin/library?a=p\&p=

about\&c $=$ envl

http://wwf.panda.org

http://povertyandconservation.info/en/bibliographies

http://protectedareasandgovernance.groupsite.com

http://www.rainforestportal.org/

http://www.tropicalforests.ox.ac.uk

http://www.un.org/Depts/dhl/

http://www.undp.org/content/undp/en/home/

librarypage.html/, http://sgp.undp.org/

http://web.undp.org/gef/gef_library.shtml

http://www.unep-wcmc.org/

http://www.unep.org,

http://ekh.unep.org/

http://www.wcs.org

http://web.worldbank.org

\section{Bibliographic searches}

Reference lists of relevant review studies will be searched for relevant primary articles.

\section{Search terms}

The following English search terms and their various combinations using Boolean operators (AND, OR), wild-cards (for any group of characters (*) or for a single character $(\$)$ ) will be used to perform search in the databases and Internet search engines. Search strings will be adapted to different formats and requirements of databases and search engines to be explored. Specifically, if a website does not allow for complex search strings and Boolean operators, we will use simple search terms such as "protected area", "governance", "park", "reserve”, "biodiversity”, "conservation”.

1) Search string for PA governance and management regimes

"NGO*" OR (non\$governmental and organi\$ation) OR "private nature reserve" oR "privat" OR

"governme*" OR "community conserved area*" OR "indigenous" or ("comanag" or "co-manag*") OR "collaborative" OR "decentrali*" OR "devolut*" OR "joint management" OR (delegat* AND authorit") OR ("integrated and conservation and development") or "ICDP*" or "governance" or "selfgovernance" or "institution" ${ }^{*}$ " or "rule" or "norm" or "polit*" or "polic" or "paper park" OR "participat" or "accountab" or "legitima" or "compliance" or "enforcement" or "coercion" or "trust" or "conflict"” or "exclusion" or "access" or "local elite" ${ }^{*}$ or "elite capture" or "revenue\$sharing" AND

"protected area*" OR "nature reserve*" OR park" OR "monument" OR "wilderness area*" OR "world heritage site*" or "sanctuar*" or "refug*" or "biosphere reserve" ${ }^{*}$ or "protected landscape" or "management area*" or "sacred forest" or "sacred grove*" $^{* \text { " }}$

AND

forest*

2) Search string for social outcomes "attitude*" OR "behavi" OR "perception" "belief:" OR "perspective"

3) Search string for ecological outcomes "conserv"*" or "deforest"* or "degrad"* or "biodiversity" or desert" or "threaten" or "leakage*" or ("spillover" or "spill-over") or "reforest" or "afforest" or ("re-growth" or "regrowth") Or "forest clearance" or "land use change" or "land cover change" or "loss"

We will combine search strings as follows: 1 AND (2 OR 3). 
Search strings developed above are the result of numerous iterations performed in ISI Web of Knowledge database. Full record of iterations has been kept and will be further developed while advancing the search. Citations will be imported into an Endnote library and online systematic review software EPPI-reviewer 4.0 [52]. Duplicates will be deleted.

\section{Study inclusion criteria}

Relevant documents will be selected by application of inclusion criteria. Inclusion criteria will be first applied to the document title, after to the abstract and in the final phase, to the whole document.

To filter studies based on abstracts, two reviewers will apply inclusion criteria. Repeatability of the application of inclusion criteria will be inspected using Kappa statistics on a sample of abstracts to assess the level of agreement between two reviewers. In case of kappa $<0.6$, inclusion criteria will be discussed, re-interpreted and adjusted if necessary. After this procedure is done, only one reviewer will apply inclusion criteria to the rest of the studies.

Relevant subject populations: Biodiversity indicators within and human populations living in and/or around forest PAs.

Relevant interventions/phenomena of interest: Forest PAs under government, co-managed or joint, private and community modes of governance worldwide.

Relevant comparators: comparisons among different interventions (governance regimes). They will follow the appropriate study design explained below. Studies without relative comparators may be included into analysis as well. Comparators reported within the qualitative study can be created using perceptions or reconstructing the memories of respondents. If present in the study, constructed comparators where external data sets or models are applied to develop scenarios for comparison will be also included into our analysis.

Relevant outcomes:

1) Changes or differences in attitudes of local stakeholders towards focal PA governance, authority and/or management practices;

2) Changes or differences in level of conservationoriented behaviour necessary to decrease the threats to natural resources;

3) Changes or difference in deforestation rate, biodiversity level within a forest ecosystem, maintenance of forest cover and forest density, condition, health (including fires);

4) Social, institutional and ecological changes on the local level that may include for example leakage (i.e. increased pressures on resources shifted outside a focal forest PA) or policy side effects (i.e. positive or negative impacts of a policy

instrument on non-focal sectors and activities).

To be included into our analysis, a study has to report on at least two types of outcomes.

Relevant types of study design: Empirical studies using qualitative, quantitative or mixed methods that can be designed as control-intervention site comparisons/case control study, cohort study, case series, cross sectional study, interrupted time series, Before-After/ControlIntervention (BACI design), randomized control trials/ control trials.

In case of multiple evidence sources for one PA, data will be combined but the most recent evidence will be prioritised.

Language: Studies published in English.

Following studies will be excluded:

Studies with a focus on PAs that do not meet the previously mentioned definition of Forest PAs [39]. This definition is provided in the IUCN Guidelines on use of PA management categories and we will follow and consult it for further clarifications and detailed interpretation.

Studies with a focus on conservation of a single or a group of species within forest PAs.

\section{Potential reasons for heterogeneity and effect modifiers}

Set of effect modifiers (predictor variables) that can cause variation in the outcomes are expected to be as follows:

Governance and decision-making characteristics: scale of decision-making; individual versus multi-actor decision-making; nature of stakeholders' participation; level and nature of collaboration among stakeholders; Resource ownership;

Level of resource access and use by the local actors;

Presence of a local leader;

Source of PA funding;

National context: corruption and illegality,

development level, income inequality;

Human population size in and around PAs;

Type of ecosystem and climatic conditions;

Proximity of the forest PA to the urban areas roads, settlements;

PA size;

Time since PA establishment;

More effect modifiers may be recorded and extracted from the primary studies.

\section{Study quality assessment}

Under study quality assessment we refer to aspects of study design important both for reducing susceptibility 
to bias and ensuring validity with respect to the question. Depending on the methodology of a study, two quality assessment strategies may be applied:

1) Quantitative studies: Quantitative studies will assessed based on the score assigned to each of following criteria: 1) appropriateness of control cases and presence of valid counterfactual, 2) controlled for and/or minimized confounding factors, 3) study design category (from highest to lowest score): randomized control trial, non-randomized control trial, BACI (before/after/control/impact) design, interrupted time series study, case control study, cohort study, case series, cross sectional study, 4) methodology: clarity and completeness of reporting [53]. We expect that the (non)randomized control trial studies and full BACI design might be less represented in the PA literature [36], as it is difficult to meet these study design requirements in conservation policy assessment due to various reasons (non-random allocation of conservation interventions across the landscape, counterfactual thinking is not widespread in conservation assessment exercises, evaluation is usually not a built-in component of a conservation project design, etc. (see [11]:483)).

2) Qualitative studies: Qualitative studies will be assessed using Harden's methodology [54] applied in Rees et al. [55] and Pullin et al. [37]. This assessment tool uses eight study validity criteria focusing on 1) study design and methods (rigour of sampling, data collection and analysis); 2) findings (how well presented data support findings, quality of findings); 3) use of methods to assess the respondents' perspectives and experiences. A score range will be assigned to each of these criteria. A Qualitative Appraisal Tool [56] may be combined for additional assessment details and to provide guidance for a more structured quality appraisal exercise. This tool is a checklist composed of the ten questions connected to study rigour, credibility and relevance of findings.

Depending on the variability of study quality, decision for the study inclusion may be based on the overall summary score assigned to each study.

\section{Data extraction}

Data will be extracted from included studies and recorded in a spreadsheet with pre-determined coding. Extracted information across all included studies will be as follows.

\section{Study characteristics}

Objectives and focus of the study;

Study design and methodology for data collection;
Reported study biases;

Study conclusions including underlying factors of social / ecological change reported.

\section{Governance characteristics}

1) Scale of decision-making (variable with 3 levels: decision-making out of state (devolution), decisionmaking vested in lower level/local authorities (decentralization), centralized decision-making);

2) Individual versus multi-actor decision-making described through i) Diversification of stakeholders' categories (2 levels: one versus multi-actor); ii) Nature of stakeholders' participation (4 levels: proactive, consultancy, passive, none);

3) Collaboration among stakeholders in decisionmaking described through i) Level of collaboration (3 levels: formal, informal, none); ii) Nature of collaboration (3 levels: horizontal (internal), vertical (external), multilevel);

\section{Institutional, social, economical and political context in which PA governance is embedded}

Resource ownership (state, local, private, mixed); Level of resource access and use by the local actors measured through 1) IUCN PA management category (1 to 6); 2) Local community dependency on the forest resources (3 levels: high, moderate, low);

Presence of a local leader (yes/no);

Source of PA funding (4 levels: international, national/ governmental, local/communal, private);

National context: corruption and illegality (Governance index score), country development level (Human

Development Index score), income inequality

(GINI score)

Human population size around PAs (high, medium, low);

Proximity to the urban areas, roads, settlements (high, medium, low);

\section{Comparator type (if any) \\ Outcome (independent variables)}

1) Attitudinal success measured through (level of changes/difference in) attitudes of local stakeholders towards focal PA governance, authority and/or management practices (3 levels: high, moderate, low);

2) Behavioural success measured through (level of changes/difference of) level of conservation-oriented behaviour necessary to decrease the threats to natural resources (3 levels: high, moderate, low); 
3) Ecological success measured through (level of changes/difference in) deforestation rate, biodiversity level, maintenance of forest cover and forest density, condition, health (3 levels: high, moderate, low);

4) Spillover effects in surrounding social-ecological systems i.e. social, institutional and ecological changes/differences on the local level that may include leakage or policy side effects (3 levels: high, moderate, low);

\section{Additional variables/controls:}

Time since PA establishment (in years);

PA size (in $\mathrm{km}^{2}$ );

Type of ecosystem and climatic conditions (temperate, tropical, boreal);

\section{Data synthesis}

Synthesis will encompass narrative and summary findings of each study and it will be presented in a table and visualised graphically. Attitudinal, behavioural, ecological success and spillover effects will be estimated based on the aforementioned criteria of performance and inferred from the (valid) evidence reported in included studies (using descriptive levels: low, moderate, high).

In order to discern the underlying conditions and determinants of PA success, qualitative and quantitative information to be extracted from the empirical studies will be integrated by pre-determined coding (as shown above under section "Study Quality Assessment") and creation of ordinal/categorical variables that will be used in multivariate statistical analyses. Independent variables in the analyses will be 4 measures of success: attitudinal, behavioural, ecological and spillover effects. Dependent variables will be governance characteristics, institutional, economical, political and social setting (effect modifiers). The analyses will be done separately for each governance mode. Finally, comparisons will be done at the final phase and based on the regression results.

We will not infer conclusions about the comparisons between governance regimes if original studies had different counterfactual outcomes i.e. we will not contrast studies that estimated counterfactual of no protection versus counterfactual of a different governance mode. Data extraction and synthesis will be additionally refined during the review process.

In case of missing data in the included studies, we will contact authors and request relevant information.

This review will report methodologies for assessment of forest PAs governance effectiveness, data gaps and potential for future empirical research.

\section{Endnotes}

a Under effective conservation we mean positive and measurable effects of conservation policies and practices on biodiversity and target ecosystems, populations, species or habitats.

${ }^{b}$ Community conserved areas have been relatively recently internationally recognized as a PA at IUCN World Parks Congress in 2003 (Durban) and at the COP VII of CBD in 2004 (Kuala Lumpur) ([57]:1);

${ }^{\mathrm{c}}$ The outcome measures are adopted from Systematic Reviews by Brooks et al. $[32,34,53]$ that employed set of ecological, attitudinal, behavioral and economic measures of success to estimate effectiveness of conservation intervention. However, as Pullin and colleagues [37] in their review focused mainly on social-economical analysis of terrestrial PAs, this review does not assess the economical effectiveness to avoid the potential overlap

d A stakeholder in this study refers to those who affect and those affected i.e. both actively and passively involved individuals, groups or organizations in a PA governance (after [58]).

\section{Competing interests \\ The authors declare that they have no competing interests.}

\section{Authors' contributions}

BM designed the protocol, wrote and revised the manuscript. LS and AP contributed to the design and development of the protocol, discussed and commented drafts, provided theoretical and methodological guidance for the protocol. All authors read and approved the final manuscript.

\section{Acknowledgments}

This research is funded by the FONASO Erasmus Mundus fellowship. Authors would like to thank to reviewers for their valuable comments.

\section{Received: 19 October 2012 Accepted: 28 June 2013}

Published: 9 July 2013

\section{References}

1. World Bank: Forests Sourcebook: Practical Guidance for Sustaining Forests in Development Cooperation. Washington, DC; 2008. http://siteresources.worldbank org/EXTFORSOUBOOK/Resources/completeforestsourcebookapril2008.pdf.

2. FAO: Global Forest Resources Assessment 2010. Main report. FAO Forestry Paper 163. Rome: FAO; 2010. http://www.fao.org/docrep/013/i1757e/i1757e.pdf.

3. Schmitt CB, Belokurov A, Besançon C, Boisrobert L, Burgess ND, Campbell A, Coad L, Fish L, Gliddon D, Humphries K, Kapos V, Loucks C, Lysenko I, Miles L, Mills C, Minnemeyer S, Pistorius T, Ravilious C, Steininger M, Winkel G: Global Ecological Forest Classification and Forest Protected Area Gap Analysis. Analyses and recommendations in view of the 10\% target for forest protection under the Convention on Biological Diversity (CBD). 2nd revised edition. Freiburg: Freiburg University Press; 2009

4. Millennium Ecosystem Assessment (MEA) Ecosystems and Human Well-being: General Synthesis. Washington: Island Press; 2005.

5. Andam KS, Ferraro PJ, Pfaff A, Sanchez-Azofeifa GA, Robalino JA: Measuring the effectiveness of protected area networks in reducing deforestation. PNAS 2008, 105:16089-16094.

6. Jenkins CN, Joppa L: Expansion of the global terrestrial protected area system. Biol Conserv 2009, 142:2166-2174.

7. Butchart SHM, Walpole M, Collen B, van Strien A, Scharlemann JPW, et al: Global biodiversity: indicators of recent declines. Sci 2010, 328:1164-1168.

8. Naughton-Treves L, Holland M, Brandon K: The role of protected areas in conserving biodiversity and sustaining local livelihoods. Annu Rev Environ Resour 2005, 30:219-252.

9. Bruner AG, Gullison RE, Price RE, da Fonseca GAB: Effectiveness of parks in protecting tropical biodiversity. Sci 2001, 291:125-128. 
10. Nelson A, Chomitz KM: Protected Area Effectiveness in Reducing Tropical Deforestation: A Global Analysis of the Impact of Protection Status. Washington: World Bank Independent Evaluation Group; 2009.

11. Ferraro PJ, Pattanayak SK: Money for Nothing? A call for empirical evaluation of biodiversity conservation investments. PLOS Bio/ 2006, 4:482-488. [http//Www plosbiology.org/article/info\%3Adoi\%2F10.1371\%2Fjournal.pbio.0040105]

12. Sanchez-Azofeifa GA, Daily G, Pfaff A, Busch C: Integrity and isolation of Costa Rica's national parks and biological reserves: examining the dynamics of land-cover change. Biol Conserv 2003, 109:123-135.

13. Secco L, Pettenella D, Gatto P: Forestry governance and collective learning process in Italy: Likelihood or Utopia? Forest Policy and Economics 2011, 13:104-112.

14. Institute on Governance: Governance principles for protected areas in the $21^{\text {st }}$ century: a discussion paper. Ottawa; 2002. http://iog.ca/wp-content/uploads/ 2012/12/2003_June_pa_governance2.pdf.

15. Borrini-Feyerabend G, Johnston J, Pansky D: Governance of protected areas. In Managing protected areas: a global guide. Edited by Lockwood M, Worboys G, Kothari A. London: Earthscan; 2006:116-145.

16. Berkes F: Community-based conservation in a globalized world. PNAS 2007, 104:15188-15193.

17. Koontz TM, Thomas CW: What do we know and need to know about the environmental outcomes of collaborative management? Public Adm Rev 2006, 66(suppl):111-121.

18. Lemos MC, Agrawal A: Environmental governance. Ann Rev Environ Resour 2006, 31:297-325

19. Borrini-Feyerabend G: Governance of protected areas: innovations in the air.... Policy Matters 2003, 12:92-101.

20. Sikor T, Barlosius E, Scheumann W: Introduction: public-private relations and key policy issues in natural resource governance. In Public and private in natural resource governance: A false dichotomy? Edited by: Sikor T. London: Earthscan; 2008:1-21

21. Agrawal A, Gupta K: Decentralization and participation: the governance of common pool resources in Nepal's Terai. Wold Dev 2005, 33:1101-1114.

22. Baral N, Stern MJ: Looking back and looking ahead: local empowerment and governance in Annapurna Conservation Area, Nepal. Environ Conserv 2009, 37:54-63.

23. Peters GB: Governance and comparative politics. In Debating Governance. Authority, Steering, and Democracy. Edited by Pierre J. Oxford: Oxford University Press; 2000:36-53.

24. Kothari A: Protected area and people: the future of the past. Parks 2008 $17: 23-34$

25. Dudley N: Guidelines for Applying Protected Area Management Categories. Gland, Switzerland: IUCN; 2008.

26. Natcher DC, Davis S, Hickey CG: Co-management: Managing relationships, not resources. Hum Organ 2005, 64:240-250.

27. Berkes F: Evolution of co-management: Role of knowledge generation, bridging organizations and social learning. J Environ Manage 2009, 90:1692-1702

28. Nadasdy P: Reevaluating the co-management success story. Arct 2003, 56:367-380

29. Berkes F: From community-based resource management to complex systems. Ecol Soc 2006, 11:45 [http://www.ecologyandsociety.org/vol11/ iss1/art45/]

30. Rhodes M: The Scientific Objectives of the NEWGOV Project: A Revised Framework. In NEWGOV Consortium Conference: 30-31 May 2005. Florence: European University Institute; 2005.

31. Eagles PFJ: Governance models for parks, recreation and tourism. In Transforming Parks and Protected Areas: Policy and Governance in a Changing World. Edited by Hanna KS, Clark DA, Slocombe DS. London: Routledge; 2008:39-61.

32. Brooks JS, Franzen MA, Holmes CM, Grote MN, Borgerhoff Mulder M: Development as a conservation tool: Evaluating ecological, economic, attitudinal, and behavioural outcomes. CEE review 05-014 (SR20). Collaboration for Environmental Evidence; 2006. www.environmentalevidence.org/SR20.html.

33. Waylen KA, Fischer A, McGowan PJK, Thirgood SJ, MilnerGulland EJ: The effect of local cultural context on communitybased conservation interventions: evaluating ecological, economic, attitudinal and behavioural outcomes. CEE review 09-019 (SR80). Collaboration for Environmental Evidence; 2010. www. environmentalevidence.org/SR80.html.

34. Brooks JS, Waylen KA, Borgerhoff-Mulder M, Brosius P: The effect of non-local socio- political context on community-based conservation interventions: evaluating ecological, economic, attitudinal and behavioural outcomes. CEE protocol 09-021 (SR82). Collaboration for Environmental Evidence; 2010. Www. environmentalevidence.org/SR82.html.

35. Bowler D, Buyung-Ali L, Healey JR, Jones JPG, Knight T, Pullin AS: The evidence base for community forest management as a mechanism for supplying global environmental benefits and improving local welfare. CEE review 08-011 (SR48). Collaboration for Environmental Evidence; 2010. www. environmentalevidence.org/SR48.html.

36. Geldmann J, Barnes M, Coad L, Craigie I, Hockings M, Burgess B: Effectiveness of terrestrial protected areas in reducing biodiversity and habitat loss. CEE review 10-007. Collaboration for Environmental Evidence; 2013. http://www. environmentalevidence.org/SR10007.html.

37. Pullin AS, Bangpan M, Dalrymple S, Dickson K, Healey J, Hockley N, Jones J, Knight T, Oliver S: Human well-being impacts of terrestrial protected areas. Systematic review protocol 11-009. Collaboration for environmental evidence; 2012. http://www.environmentalevidence.org/SR11009.html.

38. Kothari A: Community conserved areas: towards ecological and livelihood security. Parks 2006, 16:3-13

39. Dudley N, Phillips A: Forests and Protected Areas: Guidance on the use of the IUCN protected area management categories. Best Practice Protected Area Guidelines Series No. 12. Gland and Cambridge: IUCN; 2006. http://data.iucn. org/dbtw-wpd/edocs/PAG-012.pdf.

40. Porter-Bolland L, Ellis EA, Guariguata MR, Ruiz-Mallén I, Negrete-Yankelevich S, Reyes-García V: Community managed forests and forest protected areas: An assessment of their conservation effectiveness across the tropics. For Ecol Manage 2011, 268:6-17.

41. Gaston KJ, Jackson SF, Cantu-Salazar L, Cruz-Pinon G: The ecological performance of protected areas. Annu Rev Ecol Evol Syst 2008, 39:93-113.

42. Rodrigues ASL, Andelman SJ, Bakarr MI, Boitani L, Brooks TM, Cowling RM, Fishpool LDC, da Fonseca GAB, Gaston KJ, Hoffmann M, Long JS, Marquet PA, Pilgrim JD, Pressey RL, Schipper J, Sechrest W, Stuart SN, Underhill LG, Waller RW, Watts MEJ, Yan X: Effectiveness of the global protected area network in representing species diversity. Nat 2004, 428:640-643.

43. Murray GD: Multifaceted Measures of Success in Two Mexican Marine Protected Areas. Soc Nat Res Int J 2005, 18:889-905.

44. Granderson AA: Enabling multi-faceted measures of success for protected area management in Trinidad and Tobago. Eval Program Plann 2011, 34:185-195.

45. Ferraro PJ, Hanauer MM, Sims KRE: Conditions associated with protected area success in conservation and poverty reduction. PNAS 2011, 108:13913-13918.

46. Wilshusen $P$, Brechin $S$, Forwangler $C$, West $P$ : Reinventing a square wheel: Critique of a resurgent "protection paradigm" in international biodiversity conservation. Soc Nat Resour 2002, 15:17-40.

47. Hawken IF, Granoff IME: Reimagining Park Ideals: Toward Effective Human-Inhabited Protected Areas. J Sustain For 2010, 29:122-134.

48. Brechin SR, Wilshusen PR, Fortwangler CL, West PC: Beyond the square wheel: toward a more comprehensive understanding of biodiversity conservation as social and political process. Soc Nat Resour 2002, 15:41-64.

49. Brechin SR, Murray G, Mogelgaard K: Conceptual and Practical Issues in Defining Protected Area Success: The Political, Social, and Ecological in an Organized World. J Sustain For 2010, 29:362-389.

50. Hutton J, Adams WM, Murombedzi JC: Back to the Barriers? Changing Narratives in Biodiversity Conservation. Dev Stud 2005, 32:341-370.

51. Ewers RM, Rodrigues ASL: Estimates of reserve effectiveness are confounded by leakage. Trends Ecol Evol 2008, 23:113-116.

52. Thomas J, Brunton J, Graziosi S: EPPI-Reviewer 4.0: software for research synthesis. EPPI-Centre Software. London: Social Science Research Unit, Institute of Education, University of London; 2010.

53. Brooks JS, Waylen KA, Borgerhoff Mulder M: Assessing community-based conservation projects: a systematic review and multilevel analysis of attitudinal, behavioural, ecological an economical outcomes. Environ Evid 2013, 2:1-34. http://www.environmentalevidencejournal.org/content/pdf/ 2047-2382-2-2.pdf.

54. Harden A: The quality of qualitative evidence: a review of assessment tools. In Seventh Annual International Campbell Colloquium: 14-16 May 2007. London: EPPI-Centre; 2007.

55. Rees R, Oliver K, Woodman J, Thomas J: Children's views about obesity, body size, shape and weight: a systematic review. London: EPPI-Centre, Social Science Research Unit, Institute of Education, University of London; 2009. 
56. CASP appraisal tools: Qualitative Appraisal Tool. Solut Pub Health 2006 [http://www.civilservice.gov.uk/wp-content/uploads/2011/09/QualitativeAppraisal-Tool_tcm6-7385.pdf]

57. Kothari A: Community Conserved Areas: editorial. Parks 2006, 16:1-2.

58. Grimble R, Wellard K: Stakeholder methodologies in natural resource management: a review of concepts, contexts, experiences and opportunities. Agric Syst 1997, 55:173-193.

doi:10.1186/2047-2382-2-14

Cite this article as: Macura et al.: Does the effectiveness of forest

protected areas differ conditionally on their type of governance?. Environmental Evidence 2013 2:14.

\section{Submit your next manuscript to BioMed Central and take full advantage of:}

- Convenient online submission

- Thorough peer review

- No space constraints or color figure charges

- Immediate publication on acceptance

- Inclusion in PubMed, CAS, Scopus and Google Scholar

- Research which is freely available for redistribution 